\title{
A CLINICAL SURVEY OF 20 PATIENTS SUBMITTED TO AORTIC VALVULOPLASTY
}

\author{
BY \\ R. F. P. CRONIN,* E. A. S. REID, H. J. SCOTT, AND A. R. C. DOBELL \\ From the Departments of Medicine and Surgery, The Montreal General Hospital, Montreal, Canada
}

Received March 11, 1963

Aortic stenosis occurs in approximately 25 per cent of all patients with chronic valvular disease. In patients with aortic stenosis, the appearance of symptoms of angina, syncope, or left ventricular failure indicates an average prognosis of two to three years (Bergeron et al., 1954; Anderson, 1961). This is in striking contrast to mitral stenosis in which disability may be present for many years before death. In view of the short prognosis following the onset of symptoms, it is not surprising that operative correction has been actively sought for symptomatic patients with aortic stenosis. The introduction of closed aortic valvotomy ten years ago, either by the transventricular or transaortic approach, was associated not only with a moderately high operative mortality, but also with a high incidence of late deaths attributable to inadequate relief of the stenotic lesion or the production of aortic regurgitation at operation (Abelmann and Ellis, 1959; Kraus et al., 1959). More recently, improvements in surgical technique enable the correction of this lesion to be undertaken under direct vision allowing either more definitive mobilization of the valve cusps, or replacement of part or all of the aortic valve with prosthetic material (Kirklin and Mankin, 1960).

The purpose of this paper is to report the clinical course of the first 20 patients to undergo aortic valvuloplasty at the Montreal General Hospital.

\section{Subjects AND Pre-operative Assessment}

The subjects were the first 20 consecutive patients selected to undergo aortic valvuloplasty for dominant aortic stenosis at the Montreal General Hospital A history and physical examination by at least one of the authors, chest radiograph, cardiac fluoroscopy, and 12-lead electrocardiogram were available in all patients before operation. Left heart catheterization using the transventricular approach (Brock, Milstein, and Ross, 1956) was performed in every case. Measurement of the transvalvular gradient was repeated subsequently at operation, after valvuloplasty, after discontinuation of cardiopulmonary by-pass, but before closure of the wound. The progress of the survivors has been followed for from 10 to 30 months after operation. All survivors were re-evaluated by the clinical methods cited above, but none have been recatheterized. The clinical course of the Group is summarized in Table I.

Among the 20 patients there were 7 women and 13 men. The age range of the group was 27 to 59 years, with an average age of 46 years. The salient historical points are illustrated in Fig. 1 . Of the 20 patients, 8 gave a positive history for rheumatic fever, all admitted to effort dyspnœa, and 13 suffered from angina of effort. Ten of the patients, or one-half of the group, had been treated for attacks of acute left ventricular failure, 6 had syncopal episodes, and 2 had associated coronary artery disease as evidenced by clearly documented admissions for typical myocardial

* Research Associate, National Heart Foundation of Canada. 
TABLE I

Clinical and Hemodynamic Data Obtained from 20 Patients Undergoing Aortic Valvuloplasty

\begin{tabular}{|c|c|c|c|c|c|c|c|c|c|}
\hline $\begin{array}{l}\text { 节 } \\
\text { ت्ञ }\end{array}$ & 氉臨 & 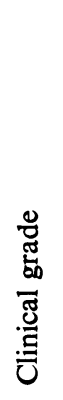 & 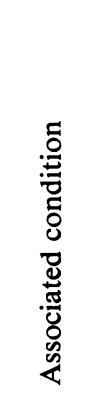 & 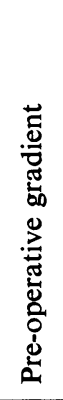 & 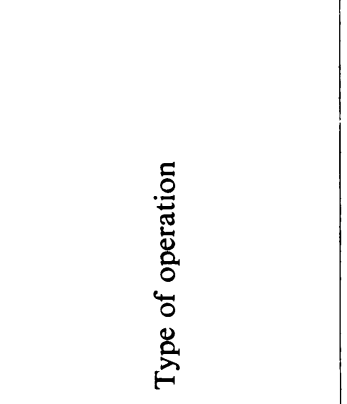 & 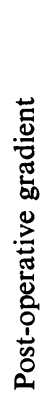 & 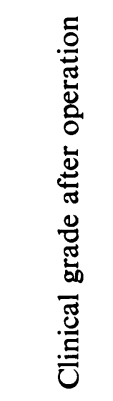 & 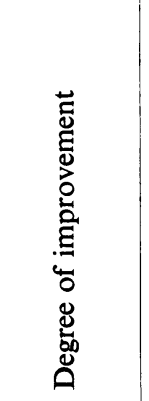 & 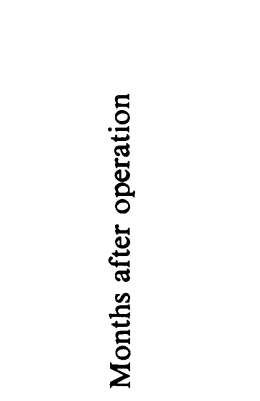 \\
\hline L.R. & $27 \mathrm{M}$ & III & & 135 & Comm. and deb. & 15 & \multicolumn{2}{|c|}{$\begin{array}{c}\text { Op. death } \\
\text { (hæmorrhage) }\end{array}$} & \\
\hline I.W. & $54 \mathrm{~F}$ & III & & 140 & Comm. and deb. & 50 & & Marked & 30 \\
\hline E.P. & $43 \mathrm{~F}$ & III & MS & 40 & Comm. (mitral and aortic) & 0 & I & Marked & 28 \\
\hline R.M. & $31 \mathrm{M}$ & II & & 55 & Comm. and deb. & 45 & II & None & 25 \\
\hline E.M. & $45 \mathrm{~F}$ & III & & 80 & Comm. and deb. & 5 & I & Marked & 24 \\
\hline J.Y. & $35 \mathrm{~F}$ & III & & 100 & Comm. and deb. & 25 & I & Marked & 23 \\
\hline C.G. & $48 \mathrm{~F}$ & III & & 100 & Comm. and deb. & 35 & II & Moderate & 21 \\
\hline E.B. & $58 \mathrm{~F}$ & III & & 120 & Comm. and P.V.R. & 75 & $\begin{array}{r}\mathrm{Op} \\
\text { (myoca }\end{array}$ & $\begin{array}{l}\text { eath } \\
\text { al failure) }\end{array}$ & \\
\hline D.R. & $54 \mathrm{~F}$ & III & & 105 & Comm. and deb. & 65 & $\begin{array}{r}\mathrm{Op} \\
\text { (myoca }\end{array}$ & $\begin{array}{l}\text { eath } \\
\text { al failure) }\end{array}$ & \\
\hline O.A. & $59 \mathrm{M}$ & IV & AHD & 70 & TVR & 0 & II & Marked & \\
\hline D.A. & $34 \mathrm{M}$ & II & & 55 & Comm. and deb. & 10 & I & Moderate & $\begin{array}{l}15 \text { late death } \\
\text { (bacterial } \\
\text { endocarditis) }\end{array}$ \\
\hline F.P. & $54 \mathrm{M}$ & III & & 90 & Comm. and deb. & 30 & I & Marked & $\begin{array}{l}13 \text { late death } \\
\text { (cause unknown) }\end{array}$ \\
\hline R.C. & $26 \mathrm{M}$ & III & MS & $\begin{array}{l}45 \\
55\end{array}$ & Comm. (mitral and aortic) & 5 & II & Moderate & 15 \\
\hline $\begin{array}{l}\text { A.B. } \\
\text { J.W. }\end{array}$ & $49 \mathrm{M}$ & II & & $\begin{array}{l}53 \\
80\end{array}$ & $\begin{array}{l}\text { TVR } \\
\text { Comm. and deb. }\end{array}$ & 15 & I & $\begin{array}{l}\text { Marked } \\
\text { Marked }\end{array}$ & 15 \\
\hline G.B. & $50 \mathrm{M}$ & III & AHD & 85 & Comm. and deb. & 30 & $\begin{array}{r}\mathrm{O} \\
\text { (myocarc }\end{array}$ & leath & \\
\hline $\begin{array}{l}\text { F.A. } \\
\text { C.L. }\end{array}$ & $\begin{array}{l}57 \mathrm{M} \\
51 \mathrm{M}\end{array}$ & $\begin{array}{l}\text { IV } \\
\text { III }\end{array}$ & & $\begin{array}{l}60 \\
75\end{array}$ & $\begin{array}{l}\text { Comm. and deb. } \\
\text { Comm. and deb. }\end{array}$ & $\begin{array}{r}20 \\
0\end{array}$ & ${ }^{\mathrm{II}}$ & Marked & 14 \\
\hline $\begin{array}{l}\text { G.D. } \\
\text { R.L. }\end{array}$ & $\begin{array}{l}37 \mathrm{M} \\
53 \mathrm{M}\end{array}$ & $\begin{array}{l}\text { III } \\
\text { III }\end{array}$ & & $\begin{array}{r}125 \\
85\end{array}$ & $\begin{array}{l}\text { Comm. and deb. } \\
\text { Comm. and deb. }\end{array}$ & $\begin{array}{r}0 \\
15\end{array}$ & $\begin{array}{c}\text { (myocarc } \\
\text { II } \\
\text { I }\end{array}$ & $\begin{array}{l}\text { infarction) } \\
\text { Moderate } \\
\text { Marked }\end{array}$ & $\begin{array}{l}12 \\
10\end{array}$ \\
\hline
\end{tabular}

MS $=$ Mitral stenosis Deb. $=$ Debridement
$\mathrm{AHD}=$ Arteriosclerotic heart disease. $\mathbf{P V R}=$ Partial valve replacement
Comm. $=$ Commissurotomy.

TVR $=$ Total valve replacement

infarction. The clinical classification of these patients in terms of their exercise tolerance, whether their limitation was due to dyspnœa alone or to a combination of dyspnœa and angina, was graded according to the criteria of the New York Heart Association (1939). Disability was assessed as grade II/IV in 3 patients, grade III/IV in 15, and 2 were in congestive heart failure at the time of operation.

The positive findings on physical examination are summarized in Fig. 2. All patients had a typical aortic ejection murmur which was grade $3 / 6$ or louder in each instance. In 17 patients this was accompanied by a palpable systolic thrill. A soft aortic diastolic murmur was present in 11 patients, but in no instance was aortic regurgitation felt to be the dominant lesion. Two had associated mitral stenosis which was corrected at the same operation, and two showed the clinical signs of right ventricular failure. 


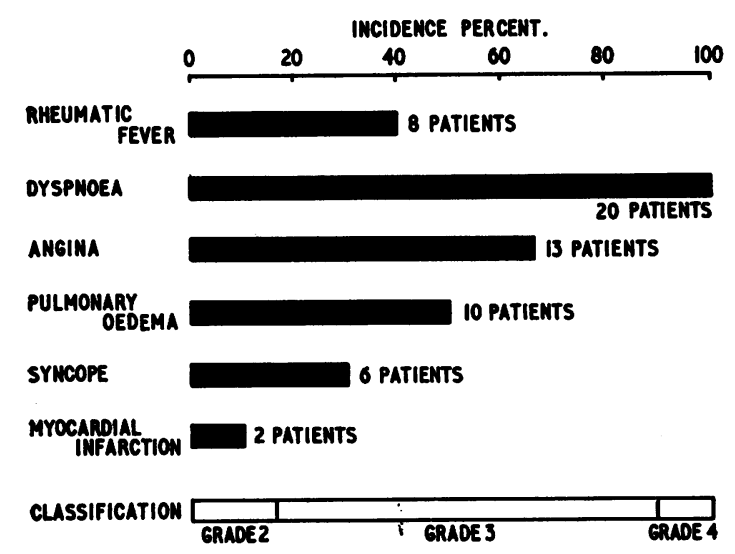

FIG. 1.-Incidence of certain symptoms and clinical classification of 20 patients undergoing operation for aortic stenosis.

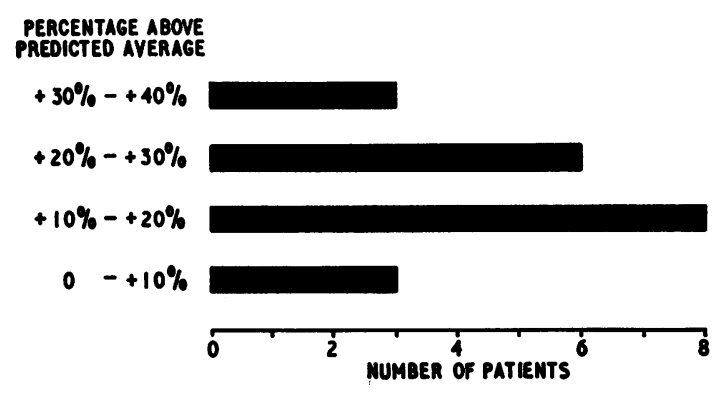

FIG. 3.-Percentage increase in transverse cardiac diameter above the predicted average as determined radiologically in the same 20 patients.

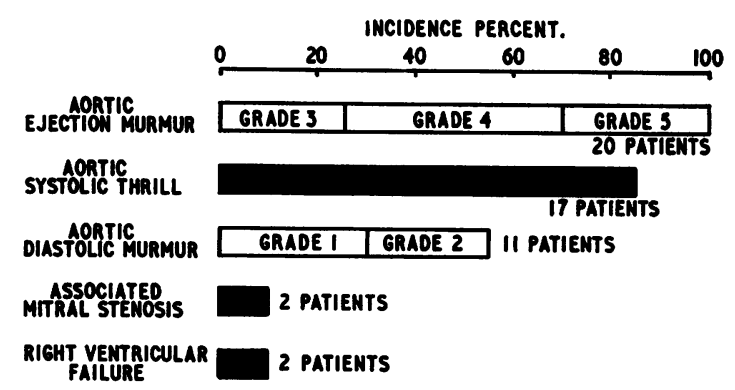

FIG. 2.-Incidence of certain physical findings in 20 patients undergoing operation for aortic stenosis.

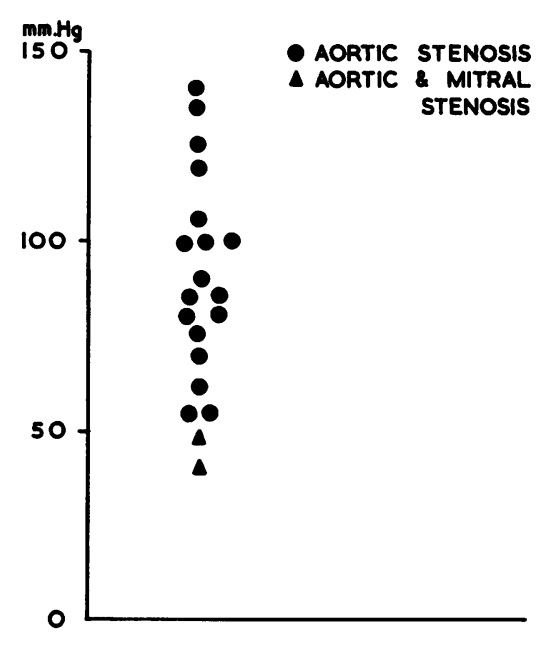

FIG. 4.-Pre-operative gradients across the aortic valve as determined at left heart catheterization.

Radiological examination showed an increased transverse cardiac diameter, as compared with the predicted average on a height-weight basis in every patient (Fig. 3). Cardiac fluoroscopy revealed moderate to severe left ventricular enlargement in every instance, and calcification of the aortic valve was visible in 15 of the 18 in whom it was present at operation. A minor degree of aortic regurgitation was demonstrated by supravalvular aortography in 6 of 8 patients in whom this procedure was carried out.

The electrocardiograms were assessed according to the criteria of Grant (1957). Left axis deviation was present in 3 and a pattern of remote myocardial infarction in 2 patients. In the 10 who were not receiving digitalis and in whom ST-T abnormalities could be adequately evaluated, left ventricular strain was present in 6, and left ventricular ischæmia in 4 patients.

The transvalvular gradients ranged from 55 to $140 \mathrm{~mm}$. $\mathrm{Hg}$ in the patients with isolated aortic stenosis, being slightly lower in the two with associated mitral stenosis (Fig. 4).

\section{Operative Technique and MoRtality}

All patients were operated on under cardiopulmonary bypass, and moderate total body hypothermia. Blood flow was maintained at $2 \cdot 41 . / \mathrm{m} .^{2}$ body surface area, with body temperature reduced to $30^{\circ} \mathrm{C}$. by a heat exchanger. The cardiac viability was maintained by coronary artery cannulation and perfusion during the period that the aortic valve was exposed. A separate pump was used to 
return arterial blood to the coronary arteries at a flow rate of $350 \mathrm{ml} . / \mathrm{min}$. This blood was at the same temperature as that perfusing the remainder of the body. In the two patients with associated mitral stenosis, non-calcific fibrous fusion of the aortic cusps was encountered, and simple aortic commissurotomy was performed. In 15 patients, commissurotomy with debridement of calcium from the valve cusps was required in order to achieve cusp mobility. In one patient a partial replacement of one cusp with a Bahnson "teflon" prosthesis was combined with commissurotomy and debridement. In the remaining two patients, total excision of all three aortic cusps was required and replacement was undertaken with Bahnson prostheses. These techniques have been described in detail elsewhere (Dobell and Scott, 1962).

A satisfactory drop in the transvalvular gradient to 30 per cent or less of the pre-operative value was obtained in all but 3 patients (Fig. 5): 2 of these died after operation with myocardial failure a contributing or predominant factor, and it was considered that inadequate valvuloplasty was the principal cause of death. In retrospect, it was considered that these two patients should have undergone total valve replacement. The third is the only one of the 15 survivors who is not clinically improved after the operation.

Five patients died from 12 hours to 6 days after operation. One died of post-operative hæmorrhage which occurred sub-pleurally from the site of the aortic puncture performed for measurement of blood pressure. This hæmorrhage was not immediately appreciated, and he died suddenly 12 hours after operation: two patients died of myocardial failure associated with an inadequate valvuloplasty, resulting in unsatisfactory lowering of the transvalvular gradient. The two remaining patients developed acute myocardial infarction, either during or shortly following operation. Both of these had moderately severe coronary artery disease, and one had had a previously documented myocardial infarction.

The post-operative complications in the 15 survivors are listed in Table I. Five of the cardiac arrhythmias proved transitory. In one patient, however, who developed complete atrio-ventricular dissociation due to block, this arrhythmia has persisted, with a ventricular rate varying between 40 and 55. Transient post-operative psychosis manifested itself in 2 patients; post-pericardiotomy syndrome has occurred in 2; and hæmologous serum jaundice in 1 patient. One developed a superficial wound infection from which a variety of organisms was cultured, and subsequently showed a mild attack of glomerulonephritis. Another developed a persistent low-grade fever 10 days after operation which was associated with one or two signs suggesting bacterial endocarditis. Although no organism was recovered from the blood-stream, he was nevertheless treated for six weeks with antibiotics: his fever has not recurred and he remains well.

\section{Post-operative Progress}

At the time of latest follow-up, which ranges from 10 to 30 months in the 15 survivors, the clinical classification and degree of improvement are illustrated in Fig. 6. Only one patient remained in the same clinical classification after operation and is therefore unimproved. Five patients reverted to the clinical classification grade immediately lower than the one they were in before operation, and were therefore classed as improved. The remaining 9 were classified two grades less than they were before operation, and are thus considered to be much improved when compared with their preoperative status.

When interviewed at follow-up, only one patient maintained that he was completely free of exertional dyspnœa (Table II). Two continued to complain of effort angina after operation: one of these had had a myocardial infarction before operation. None of the survivors noted syncope, and none were observed to have pulmonary congestive attacks. The aortic ejection murmur persisted in each of the 15 patients, but was of grade $3 / 6$ intensity or less in each. An aortic diastolic murmur, usually faint, and never more than grade $2 / 6$ intensity, was present in each of the eight patients in whom it had been heard before operation.

Objective assessment of improvement by electrocardiography and radiology did not match the 


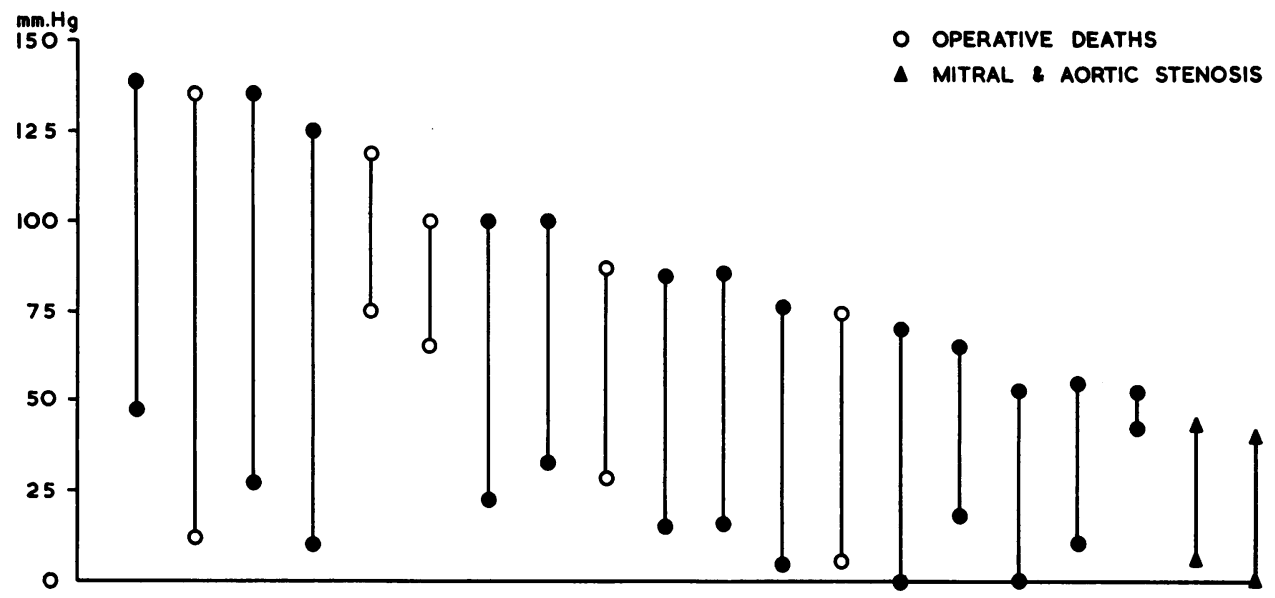

Fig. 5.-Gradients across the aortic valve obtained before and after valvuloplasty.

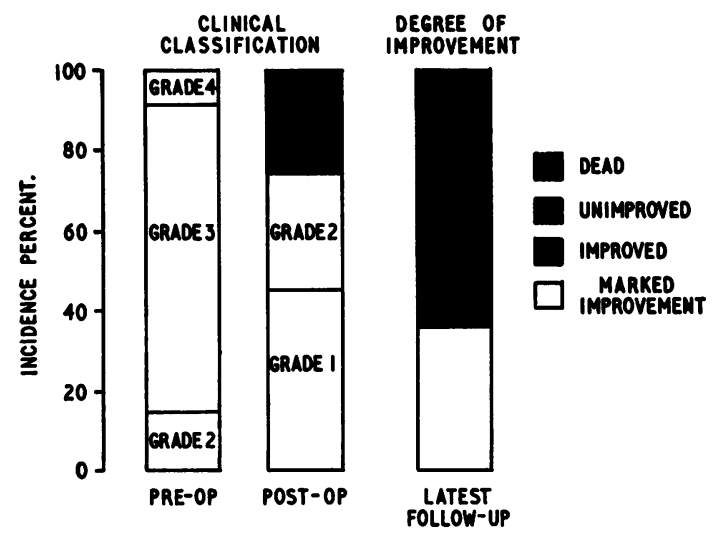

FIG. 6.-Pre- and post-operative clinical classification (left) and degree of improvement as determined at the time of latest follow-up (right).

TABLE II

Post-OPERATIVE Complications in 15 SURVivors

\begin{tabular}{|c|c|c|}
\hline Complications & & No. \\
\hline $\begin{array}{l}\text { Cardiac arrhythmias } \quad \ldots \\
\text { Atrial fibrillation } \ldots \\
\text { Paroxysmal atrial tachycardia } \\
\text { Paroxysmal ventricular tachycardia } \\
\text { Complete A-V block .. } \quad . . \\
\text { Post-pericardiotomy syndrome } \quad . \\
\text { Psychosis } \\
\text { Wound infection, glomerulonephritis } \\
\text { Homologous serum jaundice } \\
\text { Suspected bacterial endocarditis } \quad . .\end{array}$ & 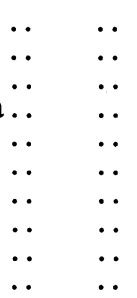 & $\begin{array}{l}3 \\
1 \\
1 \\
1\end{array}$ \\
\hline
\end{tabular}

symptomatic improvement claimed by the patients. Regression of left ventricular hypertrophy occurred in only 3 of 13 patients. Left ventricular hypertrophy with strain pattern persisted in the three survivors in whom it was present before operation, whereas the pattern of left ventricular ischæmia regressed in only one. Significant reduction in the transverse cardiac diameter, i.e. a reduction of 10 per cent or more of the predicted normal on a height-weight basis, was achieved in 5 of the 15 survivors. These 5 had had attacks of left ventricular failure or were in established congestive failure at the time of operation (Fig. 7).

Late deaths have occurred in 2 of the 15 operative survivors. One died from acute bacterial endocarditis 15 months after operation: the operative technique used in this patient was commissurotomy and debridement and he did not have prosthetic valve insertion. The other, a 54-year-old railway engineer, died suddenly at home 13 months after operation, when he was virtually symptom-free, and had returned to his former occupation: no autopsy was performed. 
TABLE III

Post-OPERATIVe Assessment in 15 Survivors

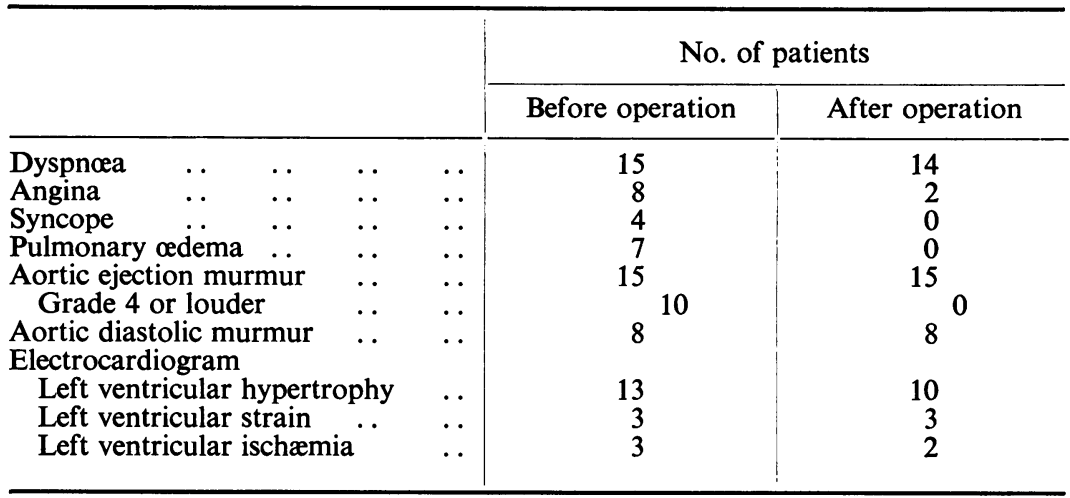

Chest radiograph showed significant reduction of transverse cardiac diameter in five patients.

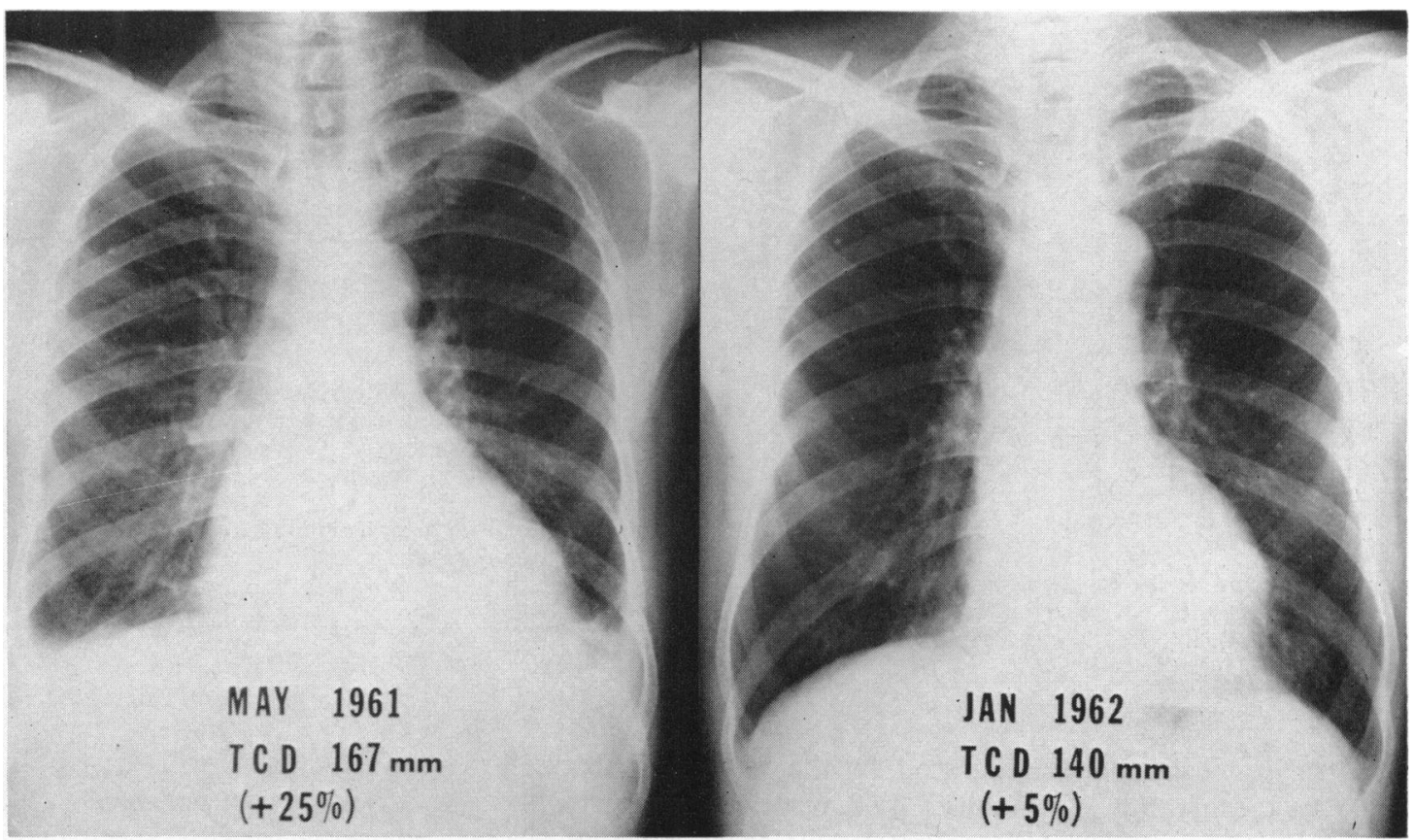

Fig. 7.-Pre- and post-operative chest radiographs in patient O.A. who underwent total valve replacement.

\section{DisCUSSION}

The serious prognosis in calcific aortic stenosis after the appearance of symptoms has been alluded to previously. Experience gained in this reported series has demonstrated that open operation for correction of this lesion can be accomplished with a hospital mortality that is no greater than that reported with closed operation. Symptomatic relief in the operative survivors has been striking, and has been most adequately maintained over a reasonably long follow-up. Many of the patients 
operated on in this series have been in the older age-group, and we have not refused operation to patients under the age of 60 years. Two of them were totally incapacitated and bed-ridden with refractory congestive cardiac failure before operation. Both these are alive and well, 14 and 20 months respectively after operation; each has been able to return to his former sedentary occupation, and neither requires cardiac medication. The especially gratifying results in these two have led us to accept for operation, patients in established heart failure, providing that the aortic valvular lesion can be shown to be the dominant cause for their disability. Coexistent coronary artery disease is most difficult to exclude as a contributing cause to a patient's disability, particularly when left ventricular failure is present, and a lowered transvalvular gradient might be expected on the basis of reduced stroke flow.

The present series is too small for statistically valid conclusions to be drawn: however, the results have been sufficiently gratifying for us to conclude that open operation for correction of aortic stenosis is now firmly established and offers the best opportunity for survival in the late stage of this disease.

\section{SUMMARY}

The clinical course of the first 20 consecutive patients undergoing open operation for correction of aortic valvular stenosis at the Montreal General Hospital has been reviewed. The operative mortality was 25 per cent. The 15 survivors have been followed for periods ranging from 10 to 30 months. Two late deaths have occurred among the operative survivors. The symptomatic improvement achieved in the survivors has been extremely gratifying. However, objective assessment of improvement, particularly in the electrocardiogram and the radiographic appearance of the heart, has not matched the symptomatic improvement. It is concluded that open operation for correction of aortic stenosis offers the best opportunity for survival in the late stage of this disease.

\section{REFERENCES}

Abelmann, W. H., and Ellis, L. B. (1959). Severe aortic stenosis in adults: Evaluation by clinical and physiologic criteria, and results of surgical treatment. Ann. intern. Med., 51, 449.

Anderson, M. W. (1961). The clinical course of patients with calcific aortic stenosis. Proc. Mayo Clin., $36,439$.

Bergeron, J., Abelmann, W. H., Vazquez-Milan, H., and Ellis, L. B. (1954). Aortic stenosis-clinical manifestations and course of the disease. Arch. intern. Med., 94, 911.

Brock, R., Milstein, B. B., and Ross, D. N. (1956). Percutaneous left ventricular puncture in the assessment of aortic stenosis. Thorax, 11, 163.

Dobell, A. R. C., and Scott, H. J. (1962). The surgical treatment of acquired valvular aortic stenosis. Canad.J. Surg., 5, 388.

Grant, R. P. (1957). Clinical Electrocardiography: The Spatial Vector Approach. McGraw-Hill, New York.

Kirklin, J. W., and Mankin, H. T. (1960). Open operation in the treatment of calcific aortic stenosis. Circulation, 21, 578 .

Kraus, W. L., Schlant, R. C., Moore, C. B., Dock, D. S., Woodward, E., Jr., Haynes, F. W., and Dexter, L. (1959). The hemodynamic results of surgery for aortic stenosis. Amer. Heart J., 58, 174.

New York Heart Association (1939). Nomenclature and Criteria for Diagnosis of Diseases of the Heart. New York Heart Association. 